\title{
The 2018 Geothermal Reservoir Stimulation in Espoo/Helsinki, Southern Finland: Seismic Network Anatomy and Data Features
}

\section{Hillers, Gregor}

2020-03

Hillers , G , Vuorinen , T A T , Uski , M , Kortström , J , Mäntyniemi , P , Tiira , T , Malin , P E \& Saarno , T 2020 , ' The 2018 Geothermal Reservoir Stimulation in Espoo/Helsinki, Southern Finland: Seismic Network Anatomy and Data Features ' , Seismological Research Letters , vol. 91 , no. 2 , pp. 770-786 . https://doi.org/10.1785/0220190253

http://hdl.handle.net/10138/326211

https://doi.org/10.1785/0220190253

acceptedVersion

Downloaded from Helda, University of Helsinki institutional repository.

This is an electronic reprint of the original article.

This reprint may differ from the original in pagination and typographic detail.

Please cite the original version. 


\title{
The 2018 geothermal reservoir stimulation in Espoo/Helsinki, southern Finland: Seismic network anatomy and data features
}

\author{
Gregor Hillers $^{1}$, Tommi A. T. Vuorinen ${ }^{1}$, Marja R. Uski ${ }^{1}$, Jari T. Kortström ${ }^{1}$, Päivi B. \\ Mäntyniemi $^{1}$, Timo Tiira ${ }^{1}$, Peter E. Malin ${ }^{2}$, Tero Saarno $^{3}$ \\ ${ }^{1}$ Institute of Seismology, University of Helsinki, Pietari Kalmin katu 5, FI-00014 University of Helsinki, Finland \\ ${ }^{2}$ ASIR Advanced Seismic Instrumentation and Research, 1311 Waterside Dallas, TX 75218-4475, USA \\ ${ }^{3}$ St1 Deep Heat Oy, Purotie 1/PL 100, 00381 Helsinki, Finland
}

Corresponding author: Gregor Hillers, gregor.hillers@helsinki.fi 


\begin{abstract}
A seismic network was installed in the Helsinki capital region of Finland to monitor the response to a $\sim 6 \mathrm{~km}$ deep geothermal stimulation experiment in 2018 . We present initial results of multiple induced earthquake seismogram and ambient wavefield analyses. The used data are from parts of the borehole network deployed by the operating St1 Deep Heat company, from surface broadband sensors and 100 geophones installed by the Institute of Seismology, University of Helsinki, and from Finnish National Seismic Network stations. Records collected in the urban environment contain many signals associated with anthropogenic activity. This results in time- and frequency-dependent variations of the signal-to-noise ratio of earthquake records from a $260 \mathrm{~m}$ deep borehole sensor compared to the combined signals of 24 co-located surface array sensors. Manual re-locations of $\sim 500$ events indicate three distinct zones of induced earthquake activity that are consistent with the three clusters of seismicity identified by the company. The fault plane solutions of 14 selected $M_{L} 0.6-1.8$ events indicate a dominant reverse-faulting style, and the associated SH radiation patterns appear to control the firstorder features of the macroseismic report distribution. Beamforming of earthquake data from six arrays suggests heterogeneous medium properties, in particular between the injection site and two arrays to the west and south-west. Ambient noise cross-correlation functions reconstruct regional surface wave propagation and path-dependent body wave propagation. A 1-D inversion of the weakly dispersive surface waves reveals average shear wave velocities around $3.3 \mathrm{~km} / \mathrm{s}$ below $20 \mathrm{~m}$ depth. Consistent features observed in relative velocity change time series and in temporal variations of a proxy for wavefield partitioning likely reflect the medium response to the stimulation. The resolution properties of the obtained data can inform future monitoring strategies and network designs in this and similar tectonic environments.
\end{abstract}




\section{Introduction}

Subsurface resource production including mining, shale gas and hydrocarbon extraction, $\mathrm{CO}_{2}$ sequestration, and deep geothermal energy capture interact with the ambient stress field. The earthquakes or other types of deformation that occur in response to these stress changes on preexisting or newly created cracks, faults, or weak zones provide important information on in-situ reservoir processes. If such activities occur in proximity to infrastructure or critical facilities the associated ground shaking or subsidence patterns can pose a nuisance or threat. A seismic network underpins the data acquisition, processing, analysis, and decision making chain in these geoengineering contexts. The properties of the network govern the resolution and thus quality of the estimated reservoir characteristics and the ability to mitigate potential unwelcome scenarios.

Networks deployed around Enhanced Geothermal System (EGS) sites [Majer et al., 2007; Evans et al., 2012; Grigoli et al., 2017] vary substantially in size and in the number of borehole and surface stations, sensor types, number of components (1-C or 3-C), telemetry, and the number of station operators, where the evolving network anatomy generally reflects the project stage [Bohnhoff et al., 2018]. The injection depths in igneous rock volumes vary commonly between $3.6 \mathrm{~km}$ as in the Cooper basin, Australia [Baisch et al., 2015], and $9.1 \mathrm{~km}$ at the scientific drilling project KTB, Germany [Baisch et al., 2002]. Surface sensors are typically installed within a radius of two [Baisch et al., 2002; Dorbath et al., 2009] to five [Baisch et al., 2015] times the reservoir depth around the stimulation site, but induced earthquakes have also been studied using data collected hundreds of kilometers away by stations that were not specifically deployed for a stimulation project [Deichmann and Giardini, 2009; Diehl et al., 2017; Grigoli et al., 2018; Ellsworth et al., 2019]. The borehole sensor depths are either shallow, such as the $80 \mathrm{~m}$ to $120 \mathrm{~m}$ deep sensors around Insheim and Landau, Germany [Vasterling et al., 2017; Küperkoch et al., 2018], or deep like the $300 \mathrm{~m}$ to $4700 \mathrm{~m}$ deep sensors around the Basel, Switzerland, reservoir [Häring et al., 2008].

Interesting extensions to these general trends include mini surface arrays [Sick and Joswig, 2017] and downhole arrays [Hofmann et al., 2019] for improved detection capabilities, dense networks for high-resolution imaging [Lehujeur et al., 2017], but also single-station methods for long-term seismicity analysis [Herrmann et al., 2019]. Various ownership and accessibility lead to analyses based on different data subsets, notably in the case of large and controversial events such as the M3.5 and M5.5 events in Basel [Häring et al., 2008; Deichmann 
and Giardini, 2009] and Pohang, South Korea [Grigoli et al., 2018; Kim et al., 2018; Ellsworth et al., 2019].

Here we discuss the anatomy and data features of a network consisting of 3-C borehole and surface stations deployed in an urban environment to monitor the response to the 2018 EGS stimulation in the capital region of Helsinki, Finland. Many of the seismic network elements used in previous cases are combined in the deployment including the deep borehole string, the single borehole sensors, regional and local broadband and short period surface stations, and three arrays with 4 and 25 stations each. The diverse network components and the overall dense instrumentation facilitate a wide range of analysis techniques for an improved resolution of the processes associated with the unprecedented stimulation of a $\sim 6 \mathrm{~km}$ deep competent bedrock unit below a major population center. For example, the high-quality earthquake records obtained in the absence of a dissipating sedimentary layer allow for systematic tests of the frequency and noise level dependent performances of borehole stations and surface arrays that can inform future acquisition strategies around natural laboratories. Data collected by the less frequently used surface arrays can be used to test and develop alternative processing tools based on beamforming or backprojection concepts for improved event detection and localization. More generally, the configuration provides data to advance event based and ambient noise based approaches for complementary imaging, monitoring, and reservoir characterization.

In this note we discuss properties of the obtained records with a focus on data from the temporary deployment of 100 short period instruments. We provide an overview of initial results based on induced earthquake seismogram (Section 5) and ambient noise (Section 6) processing that together demonstrate the potential of the collected dataset to underpin a diverse, comprehensive, multi-faceted stimulation response analysis.

\section{The stimulation}

From 4 June to 22 July 2018 (day of year 155 to 203) the operating St1 Deep Heat company stimulated a geothermal reservoir at $6.1 \mathrm{~km}$ depth to support local district heating [Kwiatek et al., 2019]. During the 49 days of the experiment about $18000 \mathrm{~m}^{3}$ water was injected in five stages that were meant to stimulate five different sections of rock in a hole-upward sequence. The drilling site is situated on the campus of the Aalto University in Otaniemi, Espoo, the neighboring city west of Helsinki, southern Finland (Figure 1a). The exceptional depth of the borehole is required due to the comparatively shallow geothermal gradient in the Fennoscandian 
Shield. The temperature at the bottom of the hole was estimated to be $130^{\circ} \mathrm{C}$, compared to the $160^{\circ} \mathrm{C}, 190^{\circ} \mathrm{C}$, and $270^{\circ} \mathrm{C}$ at $3.6 \mathrm{~km}, 5 \mathrm{~km}$, and $9.1 \mathrm{~km}$ depth estimated in Soultz-sousforêts, France [Dorbath et al., 2009], Basel [Häring et al., 2008], and the KTB [Baisch et al., 2002].

The operation-stopping magnitude limit of the the employed Traffic Light System (TLS) [Ader et al., 2019] was $M_{L} 2.1$. The tuning of the pumping parameters [Kwiatek et al., 2019] limited the magnitude of the largest induced event to 1.8 , which occurred during Stage 4 on 8 July 2018 at 17:36:37 UTC. The pumping strategy was guided by the model of Galis et al. [2017] and followed a cyclic protocol with inactive periods to allow the induced hydraulic energy to dissipate. The observed scaling between maximum magnitude and injected volume was found to be compatible with the model predictions [Kwiatek et al., 2019]. After the limit-exceeding M3.4, M3.5, and M5.5 earthquakes induced by the Basel [Häring et al., 2008], St. Gallen, Switzerland [Diehl et al., 2017], and Pohang [Ellsworth et al., 2019] stimulations, the mitigation of the induced earthquake magnitudes constitutes an intriguing showcase for future stimulation protocols.

\section{The network}

The operator deployed $243-\mathrm{C}$ borehole seismometers to monitor the induced seismicity in real-time and for the reservoir characterization [Ader et al., 2019; Kwiatek et al., 2019]. A satellite network consisting of 12 seismometers with $500 \mathrm{~Hz}$ sampling rate is installed between $240 \mathrm{~m}$ and $1150 \mathrm{~m}$ depth at distances between $0.6 \mathrm{~km}$ and $8.2 \mathrm{~km}$ around the wellhead (black stations in Figure 1a). A $2 \mathrm{kHz}$ sampling 12-level vertical borehole array is installed between $2200 \mathrm{~m}$ and $2650 \mathrm{~m}$ depth in the OTN-2 well $10 \mathrm{~m}$ offset from the main $6.4 \mathrm{~km}$ long OTN-3 well [Kwiatek et al., 2019]. The operator deployed further a 14-station accelerometer network in the area for the TLS operation [Ader et al., 2019] and several microphones to study seismo-acoustic phenomena. Data from the 12 single borehole sensors have been transmitted to the Institute of Seismology, University of Helsinki (ISUH), as part of a regulatory agreement with the city of Espoo, and are used here. Continuous borehole station recording started in April 2018. Data acquisition and transfer after the stimulation was interrupted during the 2018-2019 winter months due to insufficient power supply generated by the solar panels.

The ISUH routine analysis uses broadband data collected by the Finnish National Seismic Network (FNSN) and selected stations in the neighboring countries (Figure 1b). The used FNSN stations sample at $250 \mathrm{~Hz}$ and $100 \mathrm{~Hz}$. ISUH deployed five $250 \mathrm{~Hz}$ sampling Nano- 
metrics Compact 3-C broadband sensors HEL1 to HEL5 between September 2016 and February 2017 within a $10 \mathrm{~km}$ radius around the well head (blue stations in Figure 1a) to monitor the EGS seismicity independently and at times when the boreholes stations are not operational.

An EGS stimulation allows the observation and investigation of seismic phenomena on the intermediate scales between laboratory and tectonic boundary scales in a partially controlled in-situ environment. Here, the "downtown Finland" location puts further emphasis on the research community's ability to properly inform and educate the public based on independent analysis. To meet this mission ISUH installed a temporary network within $6 \mathrm{~km}$ around the wellhead consisting of nominally $1004.5-\mathrm{Hz} 3-\mathrm{C}$ geophones from the Geophysical Instrument Pool Potsdam (GIPP) that were connected to DATA-CUBE3 recorders (red stations in Figure 1a; hereafter referred to as cubes or cube stations). Two sensors were deployed at $13 \mathrm{~km}$ and $16 \mathrm{~km}$ distance to the east to collect data for ground motion attenuation estimates. The stations operated for 106 days between 7 May and 20 August 2018 (day 127 to 232). The GIPP instruments were deployed with built-in GPS, with the gain set to 16 , and the sampling rate set to the maximum of $400 \mathrm{~Hz}$. The stations recorded data continuously on 16 or $32 \mathrm{~GB}$ SDHC cards.

The 100 cube stations were organized in three large arrays consisting of nominally 25 stations, three small 4-station arrays, and ten single stations. The large arrays were installed in suburban, undeveloped, mostly tree-covered areas. The sensors were generally placed in the thin top soil layer that covers the ubiquitous bedrock outcrops. The array that was originally installed at the water tower location southwest to the hole was relocated after two weeks to the $1.3 \mathrm{~km}$ distant Toppelund site because of persistent vandalism. Reorganization associated with the relocation led to the final 25, 24, and 23 sensor configurations in the Seurasaari (SS), Elfvik (EV), and Toppelund (TL) arrays, respectively.

The cubes were powered by D-cell batteries. 50 stations in two large arrays used the internal 2-cell solution. The other stations were equipped with external 8-battery boxes. The deployment consumed $\sim 2200$ D-cells that were changed in an interval of $7-10$ days or $\sim 30$ days. The acquisition and maintenance benefited from the unusual warm and dry weather conditions [Sinclair et al., 2019]. Data were downloaded and cleared from the SDHC cards in the field in $\sim 35$ day intervals. The collected data volume between May and August 2018 is 280 GB from the 12 borehole sensors, 80 GB from the 5 HEL and the 3 closest FNSN stations, and 3.7 TB from the cubes [Hillers et al., 2019a]. The geophone locations were estimated with a hand-held GPS device. After the stations had been recovered in August 2018, we revisited the 
sites of the six arrays and measured the locations using a high-precision Trimble GNSS system. Here we use the initial estimates.

\section{Geological setting and data features}

The bedrock of Finland belongs to the Fennoscandian Shield, which is a part the East European Craton [Lahtinen, 2012]. The Helsinki capital region is located within the Uusimaa belt [Kähkönen, 2005] in the Southern Finland Subprovince of the Palaeoproterozoic Svecofennian domain [Nironen, 2017]. The stimulation site is located $10 \mathrm{~km}$ and $20 \mathrm{~km}$ away from two major Svecofennian crustal shear structures, the NE-SW trending Porkkala-Mäntsälä fault to the NW and the N-S trending Vuosaari-Korso fault to the E, which cut through a belt of folded and sheared volcanic and sedimentary sequences [Pajunen et al., 2008]. The crustal structure around the study area reflects the multistage accretionary and orogenic history of present-day southern Finland [Lahtinen et al., 2005], and the granites, gneisses, schists, and amphibolites in the deployment area exhibit abundant small-scale lineaments, joints, faults, and fractures [Elminen et al., 2008]. This bedrock is only locally covered by a few meters thick layer of glacial deposit or soil.

The absence of a sedimentary layer implies a high transparency for seismic waves, and the low attenuation in the crystalline rocks leads to earthquake seismograms with high signalto-noise ratio (SNR). The weak dissipation leads to discernable signals of the largest induced $M_{L} 1.8$ event at distances exceeding $400 \mathrm{~km}$ (Figure 2a). Similarly, low-magnitude events yield high-quality records at local distances (Figures $2 \mathrm{~b}-2 \mathrm{~d}$ ). It follows from the urban network environment that seismic records during working hours contain signals of the frequent explosions that are associated with many infrastructure projects (Figure 2e). Overall, the diurnal and weekly anthropogenic activity pattern leaves a clear signature in the recorded data (Figures $2 \mathrm{e}-2 \mathrm{~g})$.

\section{Seismicity analysis}

\subsection{Event sets}

ISUH compiled four different subsets of the many thousands of induced earthquakes, but although we find that the manually revised results from routine processing tools are compatible with the industrial solutions [Kwiatek et al., 2019], the application of modern automated methods [Holtzman et al., 2018; Ross et al., 2018; Bergen et al., 2008] appears inevitable to fully unlock the information contained within the collected data volumes. 
Set 1 consists of $\sim 2900$ automatically detected events that possibly include anthropogenic sources such as explosions. These are detected with a Short Term Average over Long Term Average (STA/LTA) algorithm that is adapted from the ISUH routine analysis of FNSN data and data from the neighboring countries [Kortström et al., 2018] (Figure 1b). The algorithm is applied to data from the 12 borehole stations, 5 temporary surface stations HEL1 to HEL5, and the 3 closest permanent FNSN stations MEF, NUR, and PVF at $25 \mathrm{~km}, 37 \mathrm{~km}$, and $69 \mathrm{~km}$ distance. Modified detection parameters include the five bandpass filter ranges $(4-10,10-$ $25,20-40,60-90,70-140 \mathrm{~Hz}$ ) from which the lower, central, and upper three are applied to data recorded at $100 \mathrm{~Hz}, 250 \mathrm{~Hz}$, and $500 \mathrm{~Hz}$, respectively.

Set 2 consists of the revised 490 largest events of Set 1 . Automatically picked $\mathrm{P}$ wave and S wave arrivals are manually refined by ISUH analysts. The magnitudes are estimated using a Finnish local magnitude scale [Uski and Tuppurainen, 1996] and are in the $M_{L}-0.8$ to 1.8 range. The earthquake hypocenters displayed in Figure $3 \mathrm{a}$ are computed from the revised arrival times using a standard linear least-squares algorithm. The $\mathrm{P}$ wave and $\mathrm{S}$ wave velocities are $6200 \mathrm{~m} / \mathrm{s}$ and $3620 \mathrm{~m} / \mathrm{s}$, and the $v_{P} / v_{S}$ ratio is 1.71 . These are the values of the topmost $15 \mathrm{~km}$ thick layer of the 1-D regional crustal velocity model [Kortström et al., 2018] and may thus not optimally describe the local conditions, although they are not too different from the values in the top $8 \mathrm{~km}$ of the multi-layer model used by Kwiatek et al. [2019].

Set 3 is a subset of Set 2 and consists again of the 203 largest events for which manual $\mathrm{P}$ and $\mathrm{S}$ picks from the 100 cube stations have been added to the magnitude and location estimation (Figure 3b).

Set 4 consists of 14 selected $M_{L} 0.6-1.8$ events for which we estimated the focal mechanism (Figure 3b) using manually determined polarity estimates from data from the St1, HEL, and cube networks and the three closest FNSN stations. The data set contains the six largest events $\left(M_{L} \geq 1.4\right)$ and eight smaller $\left(M_{L} 0.6-1.3\right)$ events that were selected from all areas of the stimulated volume using the initial Set 2 locations.

\subsection{Locations of induced seismicity}

The 490 Set 2 earthquake locations indicate three distinct different-sized groups of earthquake activity that are centered laterally on the SW-NE trending deep borehole section (Figure $3 a$ ). These groups are consistent with the three clusters of the industrial solutions [Kwiatek et al., 2019]. The deepest cluster containing most events is located around the bottom of the open hole at $\sim 5900 \mathrm{~m}$ depth. The overall smaller catalog size compared to Kwiatek et al. [2019] 
controls the lower resolution of the central and shallow clusters around $\sim 5500 \mathrm{~m}$ and $\sim 4900 \mathrm{~m}$ depth below and above the casing shoe, respectively, that Kwiatek et al. [2019] resolve as elongated in the $\mathrm{N} 110^{\circ} \mathrm{E}$ direction of the maximum horizontal stress. The Set 2 events are mainly located above the hole. And although the centroid of the biggest cluster in the Set 3 events based on the additional cube data (Figure 3b) is located 150-200 m deeper, it appears still $100-200 \mathrm{~m}$ shallower compared to the position found by Kwiatek et al. [2019] (their Figure $3 b)$. These variations are likely caused by different inversion and data processing strategies and velocity models.

Using data from the 12 St1, 5 HEL, and 3 FNSN stations, the RMS absolute location uncertainty for the Set 2 events is $\sim 78 \mathrm{~m}$ (Lat/Lon/Depth $38 \mathrm{~m} / 38 \mathrm{~m} / 56 \mathrm{~m}$ ) at an azimuth gap of $\sim 59^{\circ}$, compared to the bootstrap-derived $2 \sigma$ relative precision of $66 \mathrm{~m}$ for $95 \%$ of the relocated events in Kwiatek et al. [2019]. Including the cube data with the restriction of one sensor per array reduces the formal error estimate to $\sim 53 \mathrm{~m}(27 / 25 / 39)$ with an azimuth gap of $\sim 34^{\circ}$. Using all cubes for Set 3 further reduces this to $\sim 20 \mathrm{~m}(11 / 11 / 14)$ as the configuration becomes dominated by the three large arrays. Overall, the Set 2 and Set 3 event locations and the resolution of three clusters is significantly more consistent with the double-difference relocations in the "refined industrial catalog" of Kwiatek et al. [2019] compared to the realtime solutions discussed by Ader et al. [2019].

The color-coded timing in Figure 3 indicates the simultaneous activation of the three clusters during each of the five stimulation phases-an unintended aspect of the response that highlights the limits of controllability of subsurface fluid flow. The results are thus overall compatible with the findings of Kwiatek et al. [2019] who concluded based on a multiple larger event database that a preexisting "distributed fracture network" was activated instead of a "prominent, single, large fault".

\subsection{Surface and borehole data quality}

At the Elfvik location $1.5 \mathrm{~km} \mathrm{NW}$ of the injection site (Figure 1) the 24-sensor EV array and the $260 \mathrm{~m}$ deep borehole station are installed within $250 \mathrm{~m}$ horizontal distance. This proximity allows us to assess the earthquake data quality of stacked surface records compared to borehole data which can inform decisions on future monitoring network designs [Bohnhoff et al., 2018] in hard-rock environments.

As with the beamforming discussed below we apply a time shift to the bandpass-filtered vertical component array records of induced earthquakes to optimize the waveform stack as- 
sociated with each event. In a possible (near) real-time analysis, an average delay can be applied to the continuous waveforms that is estimated from the reservoir-array configuration. We discuss results obtained with two bandpass filter ranges $(10-35,60-90 \mathrm{~Hz})$ that are similar to those used in the STA/LTA analysis. For each of the 134 events - the subset of Set 3 that was available at the time of the implementation-we create $N$ different stacks consisting of $k$ randomly drawn seismograms from the 24 available records, where $k$ ranges from 1 to 24 (abscissa in Figures 4a, 4b). We limit $N$ to 12650, which is the number of possible combinations for $k=4$ from (nominally) $n=25$ different options, i.e., the binomial coefficient, and was chosen to trade-off sample size and computational load. For $k<4$ the number of unique stacks combined from the database of 24 records per event is less than 12650. Towards larger $k$ the number of unique combinations increases and then decreases again; $N>12650$ for $4 \leq k \leq 21$ and $N=1$ for $k=24$.

The P wave SNR is estimated using the $0.2 \mathrm{~s}$ STA following the STA/LTA trigger (signal) and the LTA in the $5 \mathrm{~s}$ long window preceding the trigger (noise). This SNR estimate is scaled by the similarly obtained SNR at the borehole station. Figure 4a displays a typical result from a $M_{L} 0.4$ event recorded at 24 surface sensors. The color range indicates the distribution of scaled SNRs associated with each $k$. Again, for $k=1,24$ values are obtained and binned; for $k=24$, only one stack is possible. In between, the systematic shift towards higher values implies that a random stack will increase the SNR with respect to the borehole signals. An average below unity means that the borehole waveforms are less noisy than the surface record stacks. However, the dashed line indicates there frequently exists a stacked combination of seismograms that yield better signal quality compared to the borehole waveforms. The surface deployment can thus yield similar, sometimes even better, signal-to-noise ratios of individual and of stacked seismograms. This conclusion is supported by a similar analysis of spectral SNR amplitudes in the $2-175 \mathrm{~Hz}$ range of $1.5 \mathrm{~s}$ long earthquake recorded at the two sites. We emphasize that this result depends strongly on the frequency band and the noise level, i.e., time of the day and weekday, and there is a large variability across different events. This variability prevents an explicit recommendation for a borehole sensor or a minimum number of stations in a surface array.

We assess the average station quality using this random-stack database. Figure $4 \mathrm{c}$ indicates the relative frequency in percent that each station contributes to the 100 of the 12650 stacks with the lowest SNR values using $10-35 \mathrm{~Hz}$ filtered data. Figure 4c shows the results averaged over the 134 events, and Figure $4 \mathrm{~d}$ the distribution for the largest $M_{L} 1.8$ event. 
The stacks are obtained with a constant, event-independent time shift. The color distribution clearly indicates a north-south gradient of the obtained data quality proxies. The east-west trending boundary between $y=0 \mathrm{~m}$ and $y=-20 \mathrm{~m}$ coincides with a $\sim 5 \mathrm{~m}$ high ridge of the former quarry at the EV array site. To its north is a consistently thicker vegetation mat that may be responsible for weaker coupling and hence lower data quality. A generally similar northsouth pattern is obtained for the opposite end member analysis. Whereas contributions to the 100 stacks with the highest SNR from the $M_{L} 1.8$ event data are highly compatible, the aggregate 134 event percentages are more normally distributed around a mean $40-50 \%$ contribution

\subsection{Fault plane solutions}

Focal mechanisms have been calculated for the 14 Set 4 events (Table 1, Figure 3b) using FOCMEC [Snoke, 2003]. This utilizes $\mathrm{P}$ wave polarities, $\mathrm{S}$ wave to $\mathrm{P}$ wave amplitude ratios, take-off angles, and station azimuths to determine best-fitting double-couple solutions using a grid search. The first motion polarity and amplitude of $\mathrm{P}$ waves are measured on vertical component seismogram and amplitudes of SV waves and SH waves on the radial and transverse component. Data from stations identified to be near nodal planes, noisy or of reversed polarity, are excluded from the grid search. Amplitude measurements are limited to the broadband surface HEL and FNSN stations. This limitation avoids the many data at short sourcestation distances where the amplitude ratios are very sensitive to variations in the hypocenter location. The $\mathrm{P}$ wave and $\mathrm{S}$ wave take-off angles are calculated from the velocity model described in Section 5.1. We tested several variations of this model and found that the differences in the obtained solutions were insignificant.

The grid searches generally result in a well constrained set of reverse-faulting solutions that match the polarity and amplitude observations. In contrast, the only strike-slip solution (No. 10 in Figure $3 \mathrm{~b}$ and Table 1) is less reliable as it requires allowance for three polarity errors. The fact that five of the six largest and eight other arbitrarily chosen events are all characterized by a similar reverse-faulting mechanism suggests that this faulting style plays an important role in the reservoir response. These findings motivate a more complete analysis of full moment tensor solutions that account for non-double-couple such as tensile opening components indicative of hydrofracturing [Miller et al., 1998; Ross et al., 1999; Goertz-Allmann and Wiemer, 2013; Martínez-Garzón et al., 2017] to better resolve the evolving time and space dependent faulting styles in response to the stimulation. Given the large number of temporary 
stations installed around the project site, the centers of the focal spheres are well sampled. For future deployments we learn that stations in the $10-20 \mathrm{~km}$ distance range would extend the polarity data towards the edges of the sphere, and hence yield yet better constrained solutions.

The $110-135^{\circ}$ direction of the maximum horizontal compression $\mathrm{S}_{\mathrm{Hmax}}$ [Heidbach et al., 2016] implies that faults optimally oriented in the strike-slip regime at $6 \mathrm{~km}$ depth [Kwiatek et al., 2019] would be sub-vertical and striking NW-SE to NNW-SSE [Kaisko, 2018]. This orientation is consistent with a set of local fault surface traces [Elminen et al., 2008] and it is also compatible with the majority of the strike angles S1 in Table 1. However, only the poorest constrained focal mechanism has the expected strike-slip properties, with an optimally oriented sinistral steeply dipping plane. All other solutions indicate reverse faulting along NNW-SSE striking sinistral or NNE-SSW dextral fault planes, where the associated dip angles range from shallow to moderate. This means that for the largest events, the water injection reactivated a set of pre-existing subsidiary shear fractures or faults associated with the NW-SE trending fault zones that favor reverse motion in the local stress field. The reactivated faults predominantly accommodate shortening and may accommodate horizontal shear as tensile fracturing proceeds parallel to the $\mathrm{S}_{\mathrm{Hmax}}$ orientation [Gischig and Preisig, 2015].

\subsection{Macroseismology and public response}

Observations of ground shaking can be reported using the macroseismic questionnaire of ISUH. The reports obtained online since the early 2000s reflect the overall low level of natural seismicity in the study area [Kortström et al., 2016]. The reports are mostly associated with local low-magnitude earthquakes—seven events with magnitudes between 1.1 and 2.6 occurred in the past 50 years within $50 \mathrm{~km}$ of Helsinki-, regional and global earthquakes, explosions, cryoseisms, and supersonic aircrafts [Mäntyniemi et al., 2017]. The high rate of induced earthquakes represents thus a new phenomenon that led to more frequent macroseismic reporting which documents the effects of small-magnitude induced seismic events on residents.

ISUH collected a total of 220 responses during the stimulation. The induced events were consistently observed up to distances of $7-8 \mathrm{~km}$ and occasionally at greater distances. For comparison, the natural $M_{L} 2.6$ event in March 2011 led to around 750 reports from locations within a $50 \mathrm{~km}$ radius. The number of reports appears to scale exponentially with magnitude [Ader et al., 2019]. Less than ten reports typically follow events with $M_{L}<1.7$, whereas ISUH collected 83 reports associated with the largest $M_{L} 1.8$ (Figure 5). Responses to four of the largest induced events (events $8,9,12,13$ in Table 1) with magnitudes in the $M_{L} 1.6-$ 
1.8 range contribute to more than $60 \%$ of the reports, where $38 \%$ were related to event 12 and $15 \%$ to event 13 . The anthropogenic activity pattern modulates the observation and response threshold. The $M_{L} 1.4$ event 11 on Thursday 5 July, 10:01 local time, passed almost unnoticed, whereas effects associated with the $M_{L} 1.8$ event 12 on Sunday 8 July, 20:36 local time, were widely reported.

Several respondents reported that they had been observing ground vibrations many times during some weeks before submitting their questionnaire. However, the times of these events were not specified, which challenges an overall assessment of how many induced earthquakes were observed by the general public. Figure 5 distinguishes reports on heard disturbancesthat were typically described as thunder- or blast-like-from combined shaking and sound sensations. These sound observations indicate that seismic wave energy around the lower limit of the audible frequency range couples locally to the atmosphere [Tosi et al., 2000]. The transmission of energy at frequencies that cause a variety of sensations is reflected in the reports as difficulty to describe the character and origin of the phenomena.

Whereas the observations collected by ISUH cover a range of attitudes towards the experienced disturbances, the online response system maintained by the operator collected only feedback with a positive attitude [Ader et al., 2019]. We learned that groups in access-restricted social media discussed the observed phenomena, and that a timely outreach and research system can benefit from access to and activity on such platforms. Diverse outlets need to be analyzed to obtain a more complete view on the public response and attitude.

The zonation to the NW and to the NE of the EGS site that characterizes the spatial distribution of the $M_{L} 1.8$ reports (Figure 5) is likely governed by the $\mathrm{SH}$ radiation pattern of the thrust faulting mechanism. The patterns shown in Figure 5 are the absolute values of the theoretical radiation factors for $\mathrm{SH}, \mathrm{P}$, and $\mathrm{SV}$ waves at the surface. Attenuation is not accounted for. We highlight the multiple reports from residents of buildings that are constructed on the outcropping bedrock in Munkkivuori and adjacent areas (Figure 5), where events repeatedly disrupted nighttime sleep; these neighborhoods are located in the direction of the strongest SH radiation.

We conclude that the main features of the public response pattern are, fundamentally, controlled by the tectonic situation, i.e., by the radiation pattern of reverse faults that are activated by the fluid injection. Secondary geological or societal effects such as variations in the propagation medium and local soil properties, the population density, or the affinity to report 
the phenomena likely explain the variable density of points in areas that experience similar radiation pattern controlled ground motions.

\subsection{Beamforming}

Compared to the networks associated with previous stimulation experiments, a central aspect of the 2018 Espoo/Helsinki deployment is the array of arrays, in particular the three 25-station arrays. In addition to the discussed event data quality patterns (Figure 4) the arrays facilitate antenna analysis methods [Brenguier et al., 2016; Chmiel et al., 2016] that can resolve the local propagation and provide complementary, independent constraints on medium properties and in turn on earthquake source properties. We demonstrate this by applying a timedomain delay-and-sum plane-wave beamforming approach to $\mathrm{P}$ waves of six Set 3-events with magnitudes between 1.1 and 1.8 recorded at the six arrays. The vertical component records were filtered between $2 \mathrm{~Hz}$ and $30 \mathrm{~Hz}$ and analyzed in a $1.05 \mathrm{~s}$-long window around the manually picked arrivals. Here we upsample the $400-\mathrm{Hz}$ sampled records by a factor of ten, but the first-order observations shown in Figure 6 obtained from data of a $M_{L} 1.4$ event that occurred 19 July 2018 are not sensitive to this choice.

The results shown in the slowness domain indicate that the sidelobes in the beamformer outputs are muted, even for the 4-station arrays. The obtained propagation directions indicated by the arrows in the slowness plots varies as we change the main processing parameters, notably the frequency range and the sampling rate. Results at EV show the greatest sensitivity, which we attribute to the close distance, the consequently near-vertical incidence, and the topography variations at the site. In contrast, beams obtained from the SS array are consistently very robust. In this example only six traces from the SS array were available. The results from the six analyzed events show consistently that the local propagation at the RS array to the W and at the TL array to the SW are not compatible with a homogeneous medium between source volume and array sites.

To locate the origin of the excited energy we project the beamformer output at each array along the maximum beam power to the surface. We then build the average beamformer output [Chmiel et al., 2016]. Again, for homogeneous conditions, the resulting distribution shown in Figure 6 would indicate a focus area that coincides with the earthquake hypocenter location obtained from the travel-time data. The obtained average distribution does peak near the hypocenter estimate, which demonstrates the overall applicability of the technique and the un- 
derlying model assumptions. At the same time, however, the beamformer features also show that these assumptions are too simplistic to accurately constrain the source location.

A range of extensions to the approach here can increase the consistency of the location estimates. This includes the consideration of the array topography [Bokelmann, 1995] and curved instead of plane wavefronts [Kiser and Ishii, 2017], using improved cube locations obtained with the Trimble system, removing the array response from the beam patterns [Picozzi et al., 2010; Gal et al., 2016], and applying beamforming simultanously to data from more than one array [Krüger et al., 1993]. The likely remaining inconsistencies have to be accounted for by improved 3-D velocity models that will also help to better constrain the locations obtained with travel-time based techniques. Array-derived lapse time and frequency dependent variations in the propagation can also inform about scattering time and length scales [Vernon et al., 1998; Anache-Ménier et al., 2009] that are essential observables for ambient noise based imaging and monitoring techniques.

\section{Noise based imaging and monitoring}

Empirical Green's functions estimated from cross-correlations of ambient noise records have been used to construct a detailed 3-D velocity model around the Soultz-sous-forêts and Rittershoffen sites, France [Lehujeur et al., 2017], to monitor and image a post shut-in deformation episode at the Basel EGS [Hillers et al., 2015], and to study the gas kick dynamics at the St. Gallen stimulation [Obermann et al., 2015]. Here we discuss the properties of noise cross-correlations in the $0.5-8 \mathrm{~Hz}$ frequency range obtained from the network records. We estimate an average 1-D shear velocity model based on surface wave dispersion measurements (Section 6.1) and show initial estimates of the relative velocity change variations in the stimulation period (Section 6.2).

We process data between days 130 and 230. We removed the instrument response from the data obtained from the borehole sensors, broadband stations, and the cubes. Waveforms in 1-h segments are whitened between $0.2 \mathrm{~Hz}$ and $20 \mathrm{~Hz}$, clipped at three times the standard deviation of the amplitude distribution in each window, band-pass filtered, cosine-tapered, downsampled to $50 \mathrm{~Hz}$, and cross-correlated. The full stacks are used for imaging, and daily stacks of the hourly correlations are used for monitoring. The full 9-C stacks are rotated from the ZNE to the ZRT system.

Band-pass filtered ZZ, ZR, RZ, and RR noise correlations exhibit a propagating Rayleigh wave between $0.5 \mathrm{~Hz}$ and $8 \mathrm{~Hz}$ (Figures $7 \mathrm{a}-7 \mathrm{c}$ ). The TT data show an equally clear Love wave 
(Figures $7 \mathrm{~d}-7 \mathrm{f}$ ). The move-out patterns imply a propagation speed around $3 \mathrm{~km} / \mathrm{s}$. This high value and the weak dispersion reflect the properties of the shallow bedrock. Correlations at frequencies above $1 \mathrm{~Hz}$ exhibit a high level of fluctuations before the surface wave arrivals, which we attribute to the anthropogenic noise sources within the network.

In the $2-8 \mathrm{~Hz}$ range we notice a strongly dispersive wave train that travels in a SENW direction from the SS to the EV array (Figure 7g). The strong dispersion is likely controlled by the sensitivity of the high-frequency waves to the material deposited at the bottom of the shallow Laajalahti and Maarinlahti bay. The asymmetric amplitudes suggest the city of Helsinki to the $\mathrm{E}$ of the arrays is the dominant source region. Between the TL array and the $\mathrm{PJ}$ array we resolve a $\mathrm{P}$ wave that propagates in the SSW-NNE direction with $\sim 6 \mathrm{~km} / \mathrm{s}$ (Figures 7h, 7i). A similar arrival of a wave traveling in the opposite direction can be seen at negative correlation lapse times. However, the signal strength at positive lag times is reduced when waveforms are lag time averaged, which indicates azimuthally variable excitation.

\subsection{Imaging}

We apply a fundamental mode group velocity dispersion or frequency-time analysis to lag time averaged correlation functions associated with surface station pairs to estimate average 1-D shear wave velocity models from the Rayleigh and Love waves. The approach follows Zigone et al. [2015] and Hillers and Campillo [2018] and employs a 0.3 amplitude threshold of logarithmically stacked ZZ, ZR, RZ, and RR Rayleigh wave dispersion maps, and a distance to wavelength ratio threshold of three. The resulting pair-wise dispersion curves are then averaged (Figure 8a). Rayleigh wave data support the estimate of a network average dispersion curve between $0.5 \mathrm{~Hz}$ and $6 \mathrm{~Hz}$. Figure 8a shows that the distribution branches above $3 \mathrm{~Hz}$, which implies that a 2-D lateral inversion can resolve velocity variations on the order of $10 \%$ across the study area. The Love wave dispersion curves are well resolved above $1 \mathrm{~Hz}$.

We use the GEOPSY analysis software [Wathelet, 2008] that uses the Sambridge [1999] neighborhood algorithm to estimate 1-D shear velocity $v_{S}$ profiles from the network averages. The number of layers has to be defined, and the algorithm then searches for combinations of the layer thickness and the constant body wave velocities, density, and Poisson's ratio in each layer. Here we do not constrain $v_{S}$ and couple $v_{P}$ to $v_{S}$. We process Rayleigh and Love wave dispersion data separately to assess the consistency of the solutions. Figures $8 \mathrm{~b}, 8 \mathrm{c}$ and $8 \mathrm{~d}$, 8 e display the density functions constructed from ensembles of 2500 layered $v_{S}(z)$ models associated with a 2-layer and a 5-layer parametrization. 
The 2-layer $v_{S}(z)$ models (Figure 8d) show that the velocities are reduced only in the top few tens of meters to about one third of the underlying half-space values. The low-velocity layer estimated from Rayleigh waves is with $30 \mathrm{~m}$ about twice as thick as the Love wave based estimate. If the number of parameters are increased in the 5-layer models, the topmost lowvelocity structures tend to be distributed across a depth range that reaches twice as deep-to about $60 \mathrm{~m}$ and $20 \mathrm{~m}$-as in the 2-layer models. At the same time, the $v_{S}$ distributions suggest that a wider range of multi-layer solutions can fit the data. In contrast, the $v_{S}$ values below $50 \mathrm{~m}$ depth of $\sim 3400 \mathrm{~m} / \mathrm{s}$ are consistently well constrained by the relatively non-dispersive propagation speeds of both surface wave types. Lower $v_{S}$ velocities around $1000 \mathrm{~m} / \mathrm{s}$ in the topmost few tens of meters can be associated with properties of the weathered granitic rocks. The results reflect the absence of a consistent attenuating low-velocity sedimentary layer in the study area, although thin deposits of softer material accumulates in topographic depressions.

\subsection{Monitoring}

For an initial application of passive monitoring techniques we focus on two sets of stations consisting of the 6 nearest borehole stations to the site and of 18 surface stations within a $3 \mathrm{~km}$ radius around the well bottom, where five stations each from the EV and SS arrays are used. To estimate seismic velocity changes $d v / v$ we apply the time domain stretching and the Moving Window Cross Spectral (MWCS) techniques [Lobkis and Weaver, 2003; Clarke et al., 2011] to correlation coda waveforms in a 5-25 s window at negative and positive lapse times. The long window ensures that the obtained estimates are robust but likely average over lapse time dependent $d v / v$ changes governed by systematically varying surface wave and body wave contributions [Obermann et al., 2016]. The reference waveform is the stack of correlation functions from the analysis period, days 145 to 230 . To improve the quality of the waveforms we stack correlations over \pm 1 day and apply an SVD-based Wiener filter [Moreau et al., 2017; Hillers et al., 2019b] with the dimensions five days and five samples. To assess if $d v / v$ estimates are spurious or resolve genuine medium changes we consider spectral power on the vertical $V$ and combined horizontal channels $H$, and the spectral partition ratio $H^{2} / V^{2}$ as a proxy for the $W_{\mathrm{S}}$-to- $W_{\mathrm{P}}$ energy density ratio in a diffusion regime [Shapiro et al., 2000], as markers of wavefield properties [Hillers et al., 2019b].

Time series of $d v / v$ below $0.5 \mathrm{~Hz}$ show systematic differences between component pairs involving the E component which suggests insufficient wavefield randomization and hence weak 
scattering. Two main signals are identified in the 9-C averaged $d v / v$ time series at frequencies above $0.5 \mathrm{~Hz}$ (Figures 9a, 9b). The strongest signal at $1-5 \mathrm{~Hz}$ is likely associated with the stimulation. It evolves over a period of $\sim 50$ days. The velocity reduction appears to start during the first and second stimulation phase and has its maximum during the fourth phase before it recovers rapidly during the fifth phase. This is superimposed on the second-spurioussignal, the weekly periodicity, that is strongest for the results obtained with the stretching method applied to surface station data. This weekly rhythm (Figures 2f, 2g, 9a) reflects the anthropogenic excitation pattern and the associated changes in the wavefield anatomy that is also reflected in the spectral power proxies. Note that the \pm 1 day stacking and the SVD-based Wiener filter average over the observed daily $H$ and $V$ variations.

Several indicators imply that the significant $d v / v$ change reflects the medium response to the stimulation. These indicators are that none of the visually inspected wind speed, temperature, precipitation, and atmospheric pressure records (not shown) suggest an external driving mechanism; in the $1-5 \mathrm{~Hz}$ range the amplitude of the stimulation signal is significantly larger than the spurious weekly variations; the overall similarity of stretching- and MWCSbased results, and of results obtained with surface and borehole station data; the fact that the amplitude of the signal is larger at low frequencies which suggests that the strongest medium change is not near the surface. The spectral power estimates do contain signatures of the induced seismicity (Figure 9c), but the associated variations are not compatible with the observed $d v / v$ pattern.

The overall stability of the $H^{2} / V^{2}$ marker observed at most stations also supports the inferred relation between the $d v / v$ signal and medium changes. An interesting exception are the $H^{2} / V^{2}$ estimates at the OTRA borehole and HEL2 surface stations, which are both located next to the stimulation site (Figure 1a). The ratios show very strong variations that are similar to the $d v / v$ change pattern. However, the same $d v / v$ time series are obtained if we exclude data from these stations, which implies that the velocity change estimates are not biased. In this case the $H^{2} / V^{2}$ changes, too, reflect perturbations of the medium, compatible with the $d v / v$ observations, where the strongly increasing $H^{2} / V^{2}$ ratio can be explained with an accumulating water content that reduces the $\mathrm{P}$ wave speed, since $W_{\mathrm{S}} / W_{\mathrm{P}} \propto 2 v_{\mathrm{P}}^{3} / v_{\mathrm{S}}^{3}[$ Shapiro et al., 2000].

These results warrant an in-depth analysis including the imaging of the evolving medium changes using the full data set. The stimulation data and seismicity patterns can be used to calibrate modern imaging approaches based on scattered wavefields [Blondel et al., 2018; Ober- 
mann et al., 2019], but ultimately these techniques are expected to yield independent, complementary observations of the fluid-rock interactions that possibly unfold aseismically.

\section{Conclusions}

The development and acceptance of carbon-neutral deep geothermal energy exploration depends critically on a science-based safe implementation near the consumer. After magnitude limit-exceeding earthquakes prohibited the continuation of projects in several cases, the 2018 EGS stimulation in Espoo/Helsinki, southern Finland, constitutes an encouraging case that benefited from a combination of favorable geological and stress conditions and the application of a physics-based stimulation protocol [Kwiatek et al., 2019]. We discussed properties and data features of the network that covered the stimulation. An asset the 2018 Espoo/Helsinki deployment is the combination of different network elements such as the borehole sensors, regional and local broadband and short period surface stations, and various array configurations. Such network elements were used in previous experiments, but the simultaneous deployment around the stimulation of a $\sim 6 \mathrm{~km}$ deep competent bedrock unit now allow systematic resolution tests of established methods and signal processing tools that are typically not routinely applied in an EGS context. Our overview of results obtained from induced earthquake and ambient noise analyses demonstrate the potential of the collected dataset to underpin the application of diverse approaches for extensive research on the stimulation response. Key observations from our initial analyses include the dominant anthropogenic footprint in the data, the variable quality of array earthquake records compared to colocated borehole data, the reverse faulting style of the largest events, the consistency of the SH radiation pattern with feedback from the population, the structural heterogeneity suggested by the beamformer outputs, surface and body wave propagation reconstructed from the ambient field, and the signatures in wavefield partitioning and in seismic velocity change time series that reflect the medium response to the stimulation. The resolution power of these and pending results should inform future deployment strategies around natural laboratories in general, but particularly acquisitions throughout the Fennoscandian Shield in the context of reservoir stimulation to maximize the operational and scientific gain from an EGS.

\section{Data and resources}

Data from the 12 single borehole sensors have been transmitted to the Institute of Seismology at the University of Helsinki (ISUH) as part of a regulatory agreement with the city 
of Espoo. They have not been released to the public. Data from the 12-level vertical borehole array, the accelerometers, and the microphones are proprietary and cannot be released to the public. Seismograms from the FNSN, the stations in the surrounding countries, and the five temporary monitoring stations (HEL1 to HEL5) are openly available and can be obtained by request. The 100 short period sensors and the DATA-CUBE3 loggers were provided by the Geophysical Instrument Pool Potsdam (GIPP) under the grant 201802. The standard GIPP moratorium period applies. The data can be accessed after August 312022 from the GIPP repository [Hillers et al., 2019a]. Technical information and software for translating the proprietary data format into MSEED are provided by the GIPP through its webpages. Some figures were made using The Generic Mapping Tools [Wessel et al., 2013].

\section{Acknowledgments}

The ISUH team thanks C. Haberland and the GIPP management for their support and assistance, and we thank S. Baisch, S. Wiemer, and G. Siddiqi for comments and discussions. We thank the management of the Rudolf Steiner School Espoo, Hotel Radisson Blu Espoo, Hotel Hanasaari Hanaholmen, Espoo Museum of Modern Art, Didrichsen Art Museum, GallenKallela Museum, Poliisien kesäkoti Lauttasaari, and M. Vaattovaara, T. Suontausta, and E. Katajavuori for their generous support, and S. J. H. Sarjakoski for help with the Trimble GNSS system. We thank two anonymous reviewers for comments and G. Taylor for an in-house review that helped to improve the manuscript.

\section{References}

Ader, T., M. Chendorain, M. Free, T. Saarno, P. Heikkinen, P. E. Malin, P. Leary,

G. Kwiatek, G. Dresen, F. Bluemle, and T. Vuorinen (2019), Design and implementation of a traffic light system for deep geothermal well stimulation in Finland, Journal of Seismology, doi:10.1007/s10950-019-09853-y.

Anache-Ménier, D., B. A. van Tiggelen, and L. Margerin (2009), Phase

Statistics of Seismic Coda Waves, Phys. Rev. Lett., 102(24), 248,501, doi:

10.1103/PhysRevLett.102.248501.

Baisch, S., M. Bohnhoff, L. Ceranna, Y. Tu, and H.-P. Harjes (2002), Probing the Crust to 9-km Depth: Fluid-Injection Experiments and Induced Seismicity at the KTB Superdeep Drilling Hole, Germany, Bull. Seism. Soc. Am., 92(6), 2369-2380. 
Baisch, S., E. Rothert, H. Stang, R. Vörös, C. Koch, and A. McMahon (2015), Continued Geothermal Reservoir Stimulation Experiments in the Cooper Basin (Australia), Bull. Seism. Soc. Am., 105(1), 198-209, doi:10.1785/0120140208.

Bergen, K. J., P. A. Johnson, M. V. de Hoop, and G. C. Beroza (2008), Machine learning for data-driven discovery in solid Earth geoscience, Science, 363, doi:eaau0323.

Blondel, T., J. Chaput, A. Derode, M. Campillo, and A. Aubry (2018), Matrix approach of seismic imaging: Application to the Erebus volcano, Antarctica, J. Geophy. Res. Solid Earth, 123, 10,936-10,950, doi:10.1029/2018JB016361.

Bohnhoff, M., P. Malin, J. ter Heege, J.-P. Deflandre, and C. Sicking (2018), Suggested best practice for seismic monitoring and characterization of non-conventional reservoirs, First Break, 36(2), 59-64.

Bokelmann, G. H. R. (1995), Azimuth and slowness deviations from the GERESS regional array, Bull. Seism. Soc. Am., 85(5), 1456-1463.

Brenguier, F., P. Kowalski, N. Ackerley, N. Nakata, P. Boué, M. Campillo, E. Larose, S. Rambaud, C. Pequegnat, T. Lecocq, P. Roux, V. Ferrazzini, N. Villeneuve, N. M. Shapiro, and J. Chaput (2016), Towards 4D noise-based seismic probing of volcanoes: perspectives from a large-N experiment on Piton de la Fournaise volcano, Seism. Res. Let., 87(1), doi:10.1785/0220150173.

Chmiel, M., P. Roux, and T. Bardainne (2016), Extraction of phase and group velocities from ambient surface noise in a patch-array configuration, Geophysics, 81(6), KS231KS240, doi:10.1190/GEO2016-0027.1.

Clarke, D., L. Zaccarelli, N. M. Shapiro, and F. Brenguier (2011), Assessment of resolution and accuracy of the Moving Window Cross Spectral technique for monitoring crustal temporal variations using ambient seismic noise, Geophys. J. Int., 186, 867-882, doi:10.1111/j.1365-246X.2011.05074.x.

Deichmann, N., and D. Giardini (2009), Earthquakes Induced by the Stimulation of an Enhanced Geothermal System below Basel (Switzerland), Seism. Res. Let., 80(5), 784-798, doi:10.1785/gssrl.80.5.784.

Diehl, T., T. Kraft, E. Kissling, and S. Wiemer (2017), The induced earthquake sequence related to the St. Gallen deep geothermal project (Switzerland): Fault reactivation and fluid interactions imaged by microseismicity, J. Geophy. Res. Solid Earth, 122, 72727290, doi:10.1002/2017JB014473. 
Dorbath, L., N. Cuenot, A. Genter, and M. Frogneux (2009), Seismic response of the fractured and faulted granite of Soultz-sous-Forêts (France) to $5 \mathrm{~km}$ deep massive water injections, Geophys. J. Int., 177, 653-675, doi:10.1111/j.1365-246X.2009.04030.x.

Ellsworth, W. L., D. Giardini, J. Townend, S. Ge, and T. Shimamoto (2019), Triggering of the Pohang, Korea, Earthquake $\left(M_{\mathrm{w}} 5.5\right)$ by Enhanced Geothermal System Stimulation, Seism. Res. Let., doi:10.1785/0220190102.

Elminen, T., M.-L. Airo, R. Niemelä, M. Pajunen, M. Vaarma, P. Wasenius, and M. Wennerström (2008), Fault structures in the Helsinki area, southern Finland, Geol. Surv. Finl. Spec. Pap., 47, 185-213.

Evans, K. F., A. Zappone, T. Kraft, N. Deichmann, and F. Moia (2012), A survey of the induced seismic responses to fluid injection in geothermal and $\mathrm{CO}_{2}$ reservoirs in Europe, Geothermics, 41, 30-54, doi:10.1016/j.geothermics.2011.08.002.

Gal, M., A. M. Reading, S. P. Ellingsen, K. D. Koper, R. Burlacu, and S. J. Gibbons (2016), Deconvolution enhanced direction of arrival estimation using one- and threecomponent seismic arrays applied to ocean induced microseisms, Geophys. J. Int., 206, 345-359, doi:10.1093/gji/ggw150.

Galis, M., J. Ampuero, P. Mai, and F. Cappa (2017), Induced seismicity provides insight into why earthquake ruptures stop, Sci. Adv., 3, doi:eaap7528.

Gischig, V., and G. Preisig (2015), Hydro-fracturing versus hydro-shearing: A critical assessment of two distinct reservoir stimulation mechanisms, in Proceeding to the 13th International Congress of Rock Mechanics, ISRM, Montreal, Canada, doi: 10.13140/RG.2.1.4924.3041.

Goertz-Allmann, B. P., and S. Wiemer (2013), Geomechanical modeling of induced seismicity source parameters and implications for seismic hazard assessment, Geophysics, 78(1), KS25-KS39, doi:10.1090/GEO2012-0102.1.

Grigoli, F., S. Cesca, E. Priolo, A. P. Rinaldi, J. F. Clinton, T. A. Stabile, B. Dost, M. G. Fernandez, S. Wiemer, and T. Dahm (2017), Current challenges in monitoring, discrimination, and management of induced seismicity related to underground industrial activities: A European perspective, Rev. Geophys., 55, 310-340, doi:10.1002/2016RG000542.

Grigoli, F., S. Cesca, A. P. Rinaldi, A. Manconi, J. A. López-Comino, J. F. Clinton, R. Westaway, C. Cauzzi, T. Dahm, and S. Wiemer (2018), The November $2018 M_{\mathrm{w}}$ 5.5 Pohang earthquake: A possible case of induced seismicity in South Korea, Science, (360), 1003-1006, doi:10.1126/science.aat2010. 
Häring, M. O., U. Schanz, F. Ladner, and B. C. Dyer (2008), Characterisation of the Basel 1 enhanced geothermal system, Geothermics, 37, 469-495, doi: 10.1016/j.geothermics.2008.06.002.

Heidbach, O., R. Mojtaba, K. Reiter, M. Ziegler, and W. Team (2016), World Stress Map Database Release 2016 V. 1.1., GFZ Data Services, doi:10.5880/WSM.2016.001.

Herrmann, M., T. Kraft, T. Tormann, L. Scarabello, and S. Wiemer (2019), A consistent high-resolution catalog of induced seismicity in Basel based on matched filter detection and tailored post-processing, J. Geophy. Res. Solid Earth, 124, 519-529, doi: 10.1029/2019JB017468.

Hillers, G., and M. Campillo (2018), Fault zone imaging from correlations of aftershock waveforms, Pure Appl. Geophys., 175, 2643-2667, doi:10.1007/s00024-018-1836-7.

Hillers, G., S. Husen, A. Obermann, T. Planès, E. Larose, and M. Campillo (2015), Noisebased monitoring and imaging of aseismic transient deformation induced by the 2006 Basel reservoir stimulation, Geophysics, 80(4), 51-68, doi:10.1190/GEO2014-0455.1. Hillers, G., T. A. T. Vuorinen, E. J. Arola, V. E. Katajisto, M. P. Koskenniemi, B. M. McKevitt, S. Rezaei, L. A. Rinne, I. E. Salmenperä, P. J. Seipäjärvi, L. S. O. Väkevä, A. I. Voutilainen, K. Arhe, A. K. Juntunen, J. Keskinen, P. Lindblom, K. Oinonen, and T. Tiira (2019a), A 100 3-component sensor deployment to monitor the 2018 EGS stimulation in Espoo/Helsinki, southern Finland, Dataset. GFZ Data Services, doi:10.5880/GIPP.201802.1.

Hillers, G., M. Campillo, F. Brenguier, L. Moreau, D. C. Agnew, and Y. Ben-Zion (2019b), Seismic velocity change patterns along the San Jacinto fault zone following the 2010 M7.2 El Mayor-Cucapah and M5.4 Collins Valley earthquakes, J. Geophy. Res. Solid Earth, 124, 7171-7192, doi:10.1029/2018JB017143.

Hofmann, H., G. Zimmermann, M. Farkas, E. Huenges, A. Zang, M. Leonhardt, G. Kwiatek, P. Martínez-Garzón, M. Bohnhoff, K.-B. Min, P. Fokker, R. Westaway, F. Bethmann, P. Meier, K. Yoon, J. Choi, T. Lee, and K. Kim (2019), First field application of cyclic soft stimulation at the Pohang Enhanced Geothermal System site in Korea, Geophys. J. Int., 217, 926-949, doi:10.1093/gji/ggz058.

Holtzman, B. K., A. Paté, J. Paisley, F. Waldhauser, and D. Repetto (2018), Machine learning reveals cyclic changes in seismic source spectra in Geysers geothermal field, Sci. Adv., 4, doi:eaao2929. 
Kähkönen, Y. (2005), Svecofennian supracrustal rocks, in Precambrian Geology of Finland-Key to the evolution of the Fennoscandian Shield, edited by M. Lehtinen, P. Nurmi, and O. Rämö, pp. 343-406, Elsevier, Amsterdam.

Kaisko, O. (2018), st1 Deep Heat Oy: Seismicity and possible fault structures at the Otaniemi geothermal plant site, Tech. Rep. DSTCATF-5810, ÅF-Consult Oy, Helsinki.

Kim, K.-H., J.-H. Ree, Y. Kim, S. Kim, S. Y. Kang, and W. Seo (2018), Assessing whether the $2017 M_{\mathrm{w}} 5.4$ Pohang earthquake in South Korea was an induced event, Science, (360), 1007-1009, doi:10.1126/science.aat6081.

Kiser, E., and M. Ishii (2017), Back-projection imaging of earthquakes, Annu. Rev. Earth Planet. Sci., 45, 271-299, doi:10.1146/annurev-earth-063016-015801.

Kortström, J., M. Uski, and T. Tiira (2016), Automatic classification of seismic events within a regional seismograph network, Computers \& Geosciences, 87, 22-30.

Kortström, J., M. Uski, and K. Oinonen (2018), The Finnish National Seismic Network, Summ. Bull. Internatl. Seismol. Cent., 52, 41-52, doi:10.31905/59QRNANC.

Krüger, F., M. Weber, F. Scherbaum, and J. Schlittenhardt (1993), Double beam analysis of anomalies in the core-mantle boundary region, Geophys. Res. Lett., 20(14), 14751478.

Küperkoch, L., K. Olbert, and T. Meier (2018), Long-Term Monitoring of Induced Seismicity at the Insheim Geothermal Site, Germany, Bull. Seism. Soc. Am., 108(6), 36683683, doi:10.1785/0120170365.

Kwiatek, G., T. Saarno, T. Ader, F. Bluemle, M. Bohnhoff, M. Chendorain, G. Dresen, P. Heikkinen, I. Kukkonen, P. Leary, M. Leonhardt, P. Malin, P. Martínez-Garzón, K. Passmore, P. Passmore, S. Valenzuela, and C. Wollin (2019), Controlling fluidinduced seismicity during a 6.1-km-deep geothermal stimulation in Finland, Sci. Adv., 5, doi:eaav7224.

Lahtinen, R. (2012), Main geological features of Fennoscandia, Geol. Survey of Finland, Special Paper, 53, 13-18.

Lahtinen, R., A. Korja, and M. Nironen (2005), Paleorproterozoic tectonic evolution, in Precambrian Geology of Finland-Key to the evolution of the Fennoscandian Shield, edited by M. Lehtinen, P. Nurmi, and O. Rämö, pp. 481-532, Elsevier, Amsterdam.

Lehujeur, M., J. Vergne, J. Schmittbuhl, D. Zigone, A. L. Chenadec, and E. Team (2017), Reservoir Imaging Using Ambient Noise Correlation From a Dense Seismic Network, $J$. Geophy. Res. Solid Earth, 123, 6671-6686, doi:10.1029/2018JB015440. 
Lobkis, O. I., and R. L. Weaver (2003), Coda-Wave Interferometry in Finite Solids: Recovery of $P$-to- $S$ Conversion Rates in an Elastodynamic Billiard, Phys. Rev. Lett., 90(25), doi:10.1103/PhysRevLett.90.254302.

Majer, E. L., R. Baria, M. Stark, S. Oates, J. Bommer, B. Smith, and H. Asanuma (2007), Induced seismicity associated with Enhanced Geothermal Systems, Geothermics, 36, 185-222, doi:10.1016/j.geothermics.2007.03.003.

Mäntyniemi, P., K. Oinonen, P. Seipäjärvi, and T. Vuorinen (2017), Internet macroseismology in Finland: current observatory practice, in XXVIII Geofysiikan Päivät, edited by T. Veikkolainen, L. Tuomi, T. Korja, I. Suomi, M. Nordman, M. Bilker-Koivula, and S. Väkevä, pp. 44-48, Geosfysiikan Seura (Geophysical Society of Finland).

Martínez-Garzón, P., G. Kwiatek, M. Bohnhoff, and G. Dresen (2017), Volumetric components in the earthquake source related to fluid injection and stress state, Geophys. Res. Lett., 44, 800-809, doi:10.1002/2016GL071963.

Miller, A. D., G. R. Foulger, and B. R. Julian (1998), Non-double-couple earthquakes 2. Observations, Rev. Geophys., 36(4), 551-568, doi:10.1029/98RG00717.

Moreau, L., L. Stehly, P. Boué, Y. Lu, and M. Campillo (2017), Improving ambient noise correlation functions with an SVD-based Wiener filter, Geophys. J. Int., 211, 418-426, doi:10.1093/gji/ggx306.

Nironen, M. (2017), Guide to the Geological Map of Finland-Bedrock 1:1000000, Geol. Survey of Finland, Special Paper, 60, 41-76.

Obermann, A., T. Kraft, E. Larose, and S. Wiemer (2015), Potential of ambient seismic noise techniques to monitor the St. Gallen geothermal site (Switzerland), J. Geophy. Res. Solid Earth, 120, doi:10.1002/2014JB011817.

Obermann, A., T. Planès, C. Hadziioannou, and M. Campillo (2016), Lapse-timedependent coda-wave depth sensitivity to local velocity perturbations in 3-D heterogeneous elastic media, Geophys. J. Int., 207, 59-66, doi:10.1093/gji/ggw264.

Obermann, A., T. Planès, E. Larose, and M. Campillo (2019), 4-D imaging of subsurface changes with coda waves: Numerical studies of 3-D combined sensitivity kernels and application to the $M_{\mathrm{w}}$ 7.9, 2008 Wenchuan earthquake, Pure Appl. Geophys., 176, 1243-1254, doi:10.1007/s00024-018-2014-7.

Pajunen, M., M.-L. Airo, T. Elminen, I. Mänttäri, R. Niemelä, M. Vaarma, P. Wasenius, and M. Wennerström (2008), Tectonic evolution of the Svecofennian crust in southern Finland, Geol. Surv. Finl. Spec. Pap., 47, 15-160. 
Picozzi, M., S. Parolai, and D. Bindi (2010), Deblurring of frequency-wavenumber images from small-scale seismic arrays, Geophys. J. Int., 181, 357-368, doi:10.1111/j.1365246X.2009.04471.x.

Ross, A., G. R. Foulger, and B. R. Julian (1999), Source processes of industrially-induced earthquakes at The Geysers geothermal area, California, Geophysics, 64(6), 1877-1889, doi:10.1190/1.1444694.

Ross, Z. E., M.-A. Meier, and E. Hauksson (2018), $P$ wave arrival picking and firstmotion polarity determination with deep learning, J. Geophy. Res. Solid Earth, 123, 5120-5129, doi:10.1029/2017JB015251.

Sambridge, M. (1999), Geophysical inversion with a neighbourhood algorithm-I. Searching a parameter space, Geophys. J. Int., 138, 479-494.

Shapiro, N. M., M. Campillo, L. Margerin, S. K. Singh, V. Kostoglodov, and J. Pacheco (2000), The Energy Partitioning and the Diffuse Character of the Seismic Coda, Bull. Seism. Soc. Am., 90(3), 655-665.

Sick, B., and M. Joswig (2017), Combining network and array waveform coherence for automatic location: examples from induced seismicity monitoring, Geophys. J. Int., 208, 1373-1388, doi:10.1093/gji/ggw468.

Sinclair, V. A., J. Mikkola, M. Rantanen, and J. Räisänen (2019), The summer 2018 heatwave in Finland, Weather, doi:10.1002/wea.3525.

Snoke, J. A. (2003), FOCMEC: FOCal MEChanism Determinations, in International Handbook of Earthquake and Engineering Seismology, Part B, edited by W. H. K. Lee, H. Kanamori, P. C. Jennings, and C. Kisslinger, pp. 1629-1630, Academic Press, London.

Tosi, P., V. D. Rubeis, A. Tertulliani, and C. Gasparini (2000), Spatial patterns of earthquake sounds and seismic source geometry, Geophys. Res. Lett., 27, 2749-2752.

Uski, M., and A. Tuppurainen (1996), A new local magnitude scale for the Finnish seismic network, Tectonophysics, 261, 23-37.

Vasterling, M., U. Wegler, J. Becker, A. Brüstle, and M. Bischoff (2017), Real time envelope cross-correlation detector: application to induced seismicity in the Insheim and Landau deep geothermal reservoirs, Journal of Seismology, 21, 193-208, doi: 10.1007/s10950-016-9597-1.

Vernon, F. L., G. L. Pavlis, T. J. Owens, D. E. McNamara, and P. N. Anderson (1998), Near-Surface Scattering Effects Observed with a High-Frequency Phased Array at 
Pineon Flats, California, Bull. Seism. Soc. Am., 88(6), 1548-1560.

Wathelet, M. (2008), An improved neighborhood algorithm: Parameter conditions and dynamic scaling, Geophys. Res. Lett., 35, L09301, doi:10.1029/2008GL033256.

Wessel, P., W. H. F. Smith, R. Scharroo, J. Luis, and F. Wobbe (2013), Generic Mapping Tools: Improved Version Released, EOS Trans. AGU, 94, doi:10.1002/2013EO450001. Zigone, D., Y. Ben-Zion, M. Campillo, and P. Roux (2015), Seismic Tomography of the Southern California plate boundary region from noise-based Rayleigh and Love Waves, Pure Appl. Geophys., 172, 1007-1032, doi:10.1007/s00024-014-0872-1. 


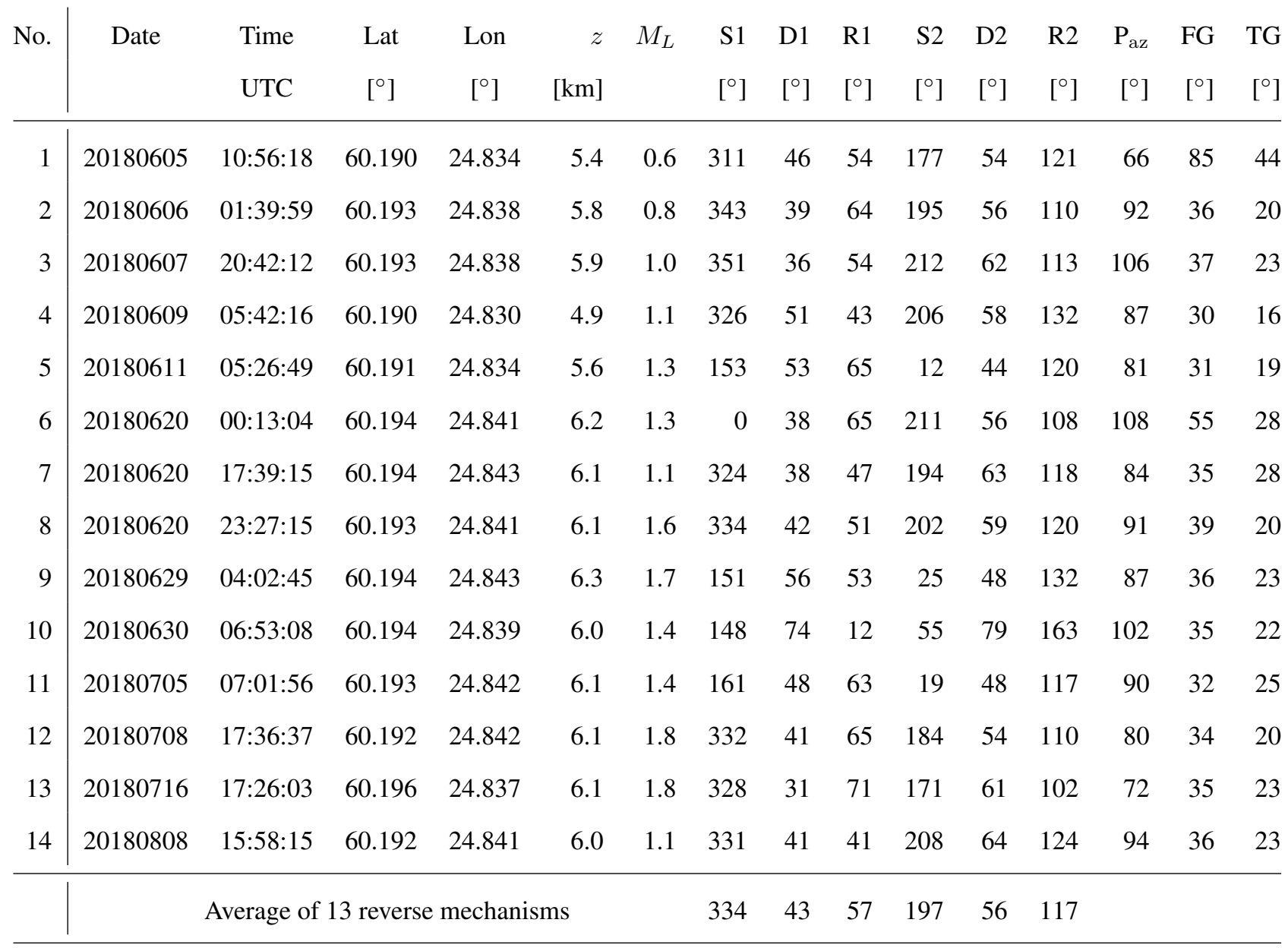

Table 1. Parameters of the obtained double-couple source mechanisms. No: Event number. $z$ : Depth. $M_{L}$ :

Local magnitude. S1, D1, R1, S2, D2, R2: strike, dip, and rake angles of the two possible fault planes. $\mathrm{P}_{\mathrm{az}}$ :

Azimuth of the P-axis or maximum horizontal compression. FG: Maximum azimuth gap between the stations providing data. TG: Take-off angle gap among the impulsive polarity data. 
Figure 1. (a) Map of the stations in the Helsinki metropolitan region. Black circles indicate the 12 borehole stations. Blue circles indicate the 5 broadband HEL stations. Red symbols indicate locations of the 100 cube stations. The orange ' $\times$ ' symbol marks the injection site, and the black line indicates the borehole trajectory. The gray square to the west of the TL array indicates its initial location before it was relocated. The insets show the geometry of the arrays at locations Elfvik (EV), Pajamäki (PM), Seurasaari (SS), Poliisin kesäkoti (PK), Toppelund (TL), and Rudolf-Steiner school Espoo (RS). (b) Finnish national network and stations in neighboring countries used in the routine analysis. The red encircled cross at $25^{\circ} \mathrm{E}, 60^{\circ} \mathrm{N}$ indicates the location of Helsinki.

Figure 2. Vertical component data examples. (a) Records from the largest induced event from selected stations in Figure 1b. (b) - (d) $2-30 \mathrm{~Hz}$ filtered seismograms of a $M_{L} 1.4$ event recorded at 20 stations of the (b) Elfvik, (c) Seurasaari, (d) Toppelund array. Traces are aligned on the picked P wave arrival. (e) 21 days long section of $0.2 \mathrm{~Hz}$ highpass filtered data recorded at the broadband station HEL1. The stimulation and the induced seismicity started on day 155. (f) - (g) Spectrograms of data recorded by the (f) Elfvik borehole station ELFV and by (g) sensor EV00 from the colocated array. The spectral power range is linear and scaled to the maximum in (g). Colorbar applies to (f) and (g). 
Figure 3. Induced earthquake locations in map view (left column) and cross section along the orientation of the open hole section (right column). (a) 490 Set 2 events. (b) 203 Set 3 events including the 14 Set 4 events for which fault plane solutions were estimated. The numbers above the focal mechanisms correspond to Table 1. Colors follow Kwiatek et al. [2019] and correspond to the different stimulation phases. Events are plotted in reverse order of occurrence.

Figure 4. Signal-to-noise ratio (SNR) evolution as a function of stack length. (a) and (b) show distributions of SNR of vertical component $\mathrm{P}$ wave seismograms from a daytime $M_{L} 0.4$ event recorded at the Elfvik EV array for an increasing number of array stations scaled by the SNR at the colocated ELFV borehole station for (a) $10-35 \mathrm{~Hz}$ and (b) $60-90 \mathrm{~Hz}$. Values grater than unity imply the SNR is higher for the surface record stacks. The dashed line indicates the maximum SNR for each number of stations, i.e., the line delineates small values for the density (below) from zero (above) (white area below the line indicate small values; white area above the line indicate zero). (c) and (d) show EV array station quality estimates. The colors indicate how often seismograms from a station contributed to 100 out of 12650 random stacks per event that have low $\mathrm{P}$ wave SNR estimates. Green and red colors indicate stations that provide on average high- and low-quality waveforms. (c) Aggregate statistics from the 134 largest events. (d) Statistics associated with the largest $M_{L} 1.8$ event.

Figure 5. SH wave radiation pattern of the largest induced event. Absolute values are shown. Filled and open circles correspond to locations from which felt and heard disturbances were reported. Locations are by street address. The white ellipse indicates Munkkivuori and adjacent neighborhoods. The solid and dashed contours correspond to the $\mathrm{P}$ wave and SV wave radiation patterns shwon in the insets. Values are scaled by the maximum in each distribution.

Figure 6. $\mathrm{P}$ wave beamforming results of a $M_{L} 1.4$ event. The six slowness domain plots show the beamformer results centered on the locations of the corresponding arrays. Small black arrows point to the maximum beamformer output. The large colored distribution indicates the horizontal average built from the six solutions. Gray lines indicate the array dependent 0.95 quantile of the mapped distributions. The black contour delimits the high-probabilty area of the obtained average solution. The white circle is the hypocenter, and the symbols in the background correspond to the stations shown in Figure 1a. 
Figure 7. (a) - (c) $\mathrm{ZZ}$ noise correlations between arrays show Rayleigh wave propagation in three frequency bands $(0.5-2,1-4,2-8 \mathrm{~Hz})$. (d) -(f) The same for Love wave propagation in TT noise correlations. The dashed line indicates a speed of $3 \mathrm{~km} / \mathrm{s}$. Gray and black lines indicate individual and array-average correlations. The correlations are lag time averaged over negative and positive lag times. (g) Highly dispersive surface wave train in the ZZ correlations between SS and EV arrays. The same frequency bands as in (a)-(c) apply. (h) 1-4 Hz ZZ correlation gather between TL and PM arrays. (i) Particle motion of the P wave and Rayleigh wave highlighted in (h).

Figure 8. Rayleigh wave (top) and Love wave (bottom) dispersion analysis. (a) Distribution of observed dispersion curves. The network average indicated by the white line is inverted for the 1-D shear wave velocity profile. (b) Distribution of dispersion curves from the 1000 best models using the 2-layer and (c) the 5-layer parametrization. (d) Distribution of 1000 best 1-D shear wave velocity profiles obtained with the 2-layer and (e) the 5-layer parametrization. The distributions in (d) and (e) in the halfspace peak at $3420 \mathrm{~m} / \mathrm{s}$ and $3420 \mathrm{~m} / \mathrm{s}$ for the Rayleigh waves, and at $3300 \mathrm{~m} / \mathrm{s}$ and $3340 \mathrm{~m} / \mathrm{s}$ for the Love waves, respectively. The colorbar applies to all panels.

Figure 9. Frequency-dependent daily relative velocity change $d v / v$ time series obtained with the (a) stretching and (b) MWCS method. Surface and borehole average results are offset for clarity. The grey lines are the solutions omitting data from the OTRA station. (c) Low, medium, and high quantiles of daily vertical and horizontal component energy estimates in the $1-5 \mathrm{~Hz}$ range. Data are averaged over all stations used in the $d v / v$ analysis. Energy levels are on a log-scale before the 100 day median was subtracted. (d)-(e) 1-5 Hz partition ratios $H^{2} / V^{2}$ at (d) surface and (e) borehole sensors. The distributions in (d) and (e) are from the HEL2 and OTRA stations. The black lines show the maximum likelihoods for data from the HEL3 and LEPP stations for comparison. The 'binary' appearance is controlled by the bin width. The sampling frequency is two samples per day. The dashed lines indicate the five stimulation stages. 
Figure 1
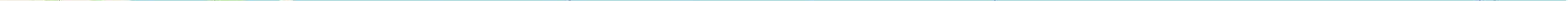

(b) 

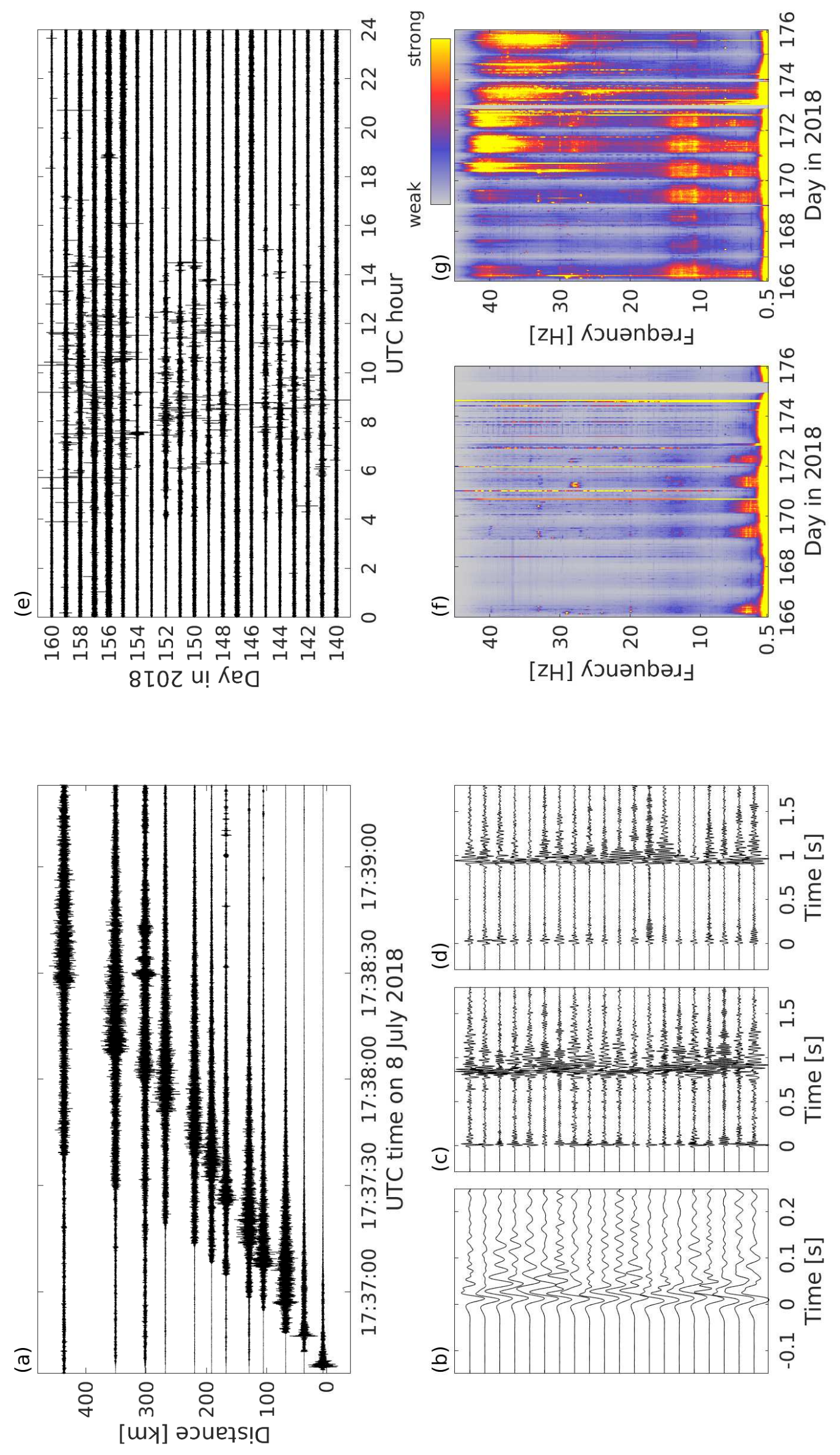

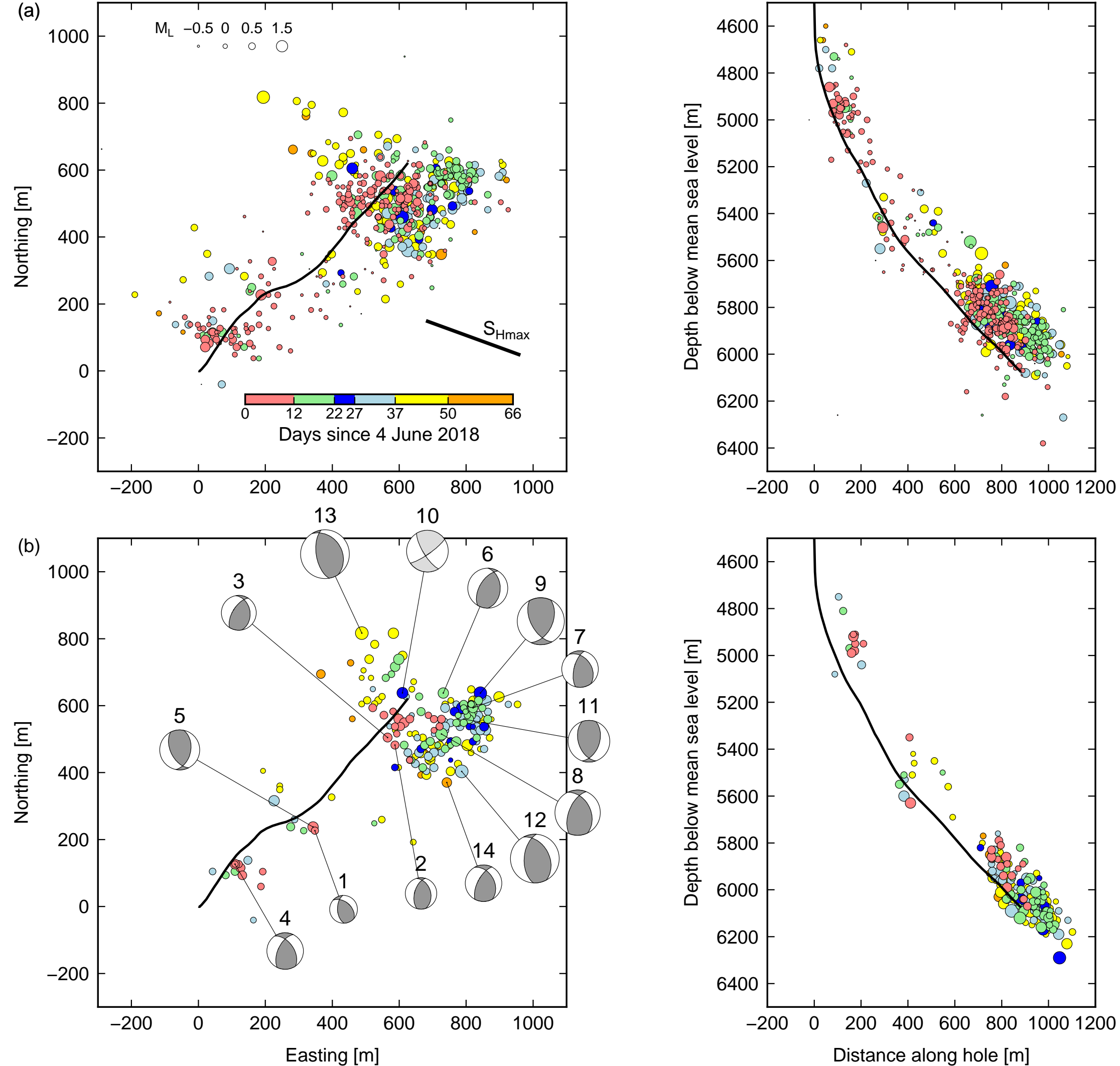

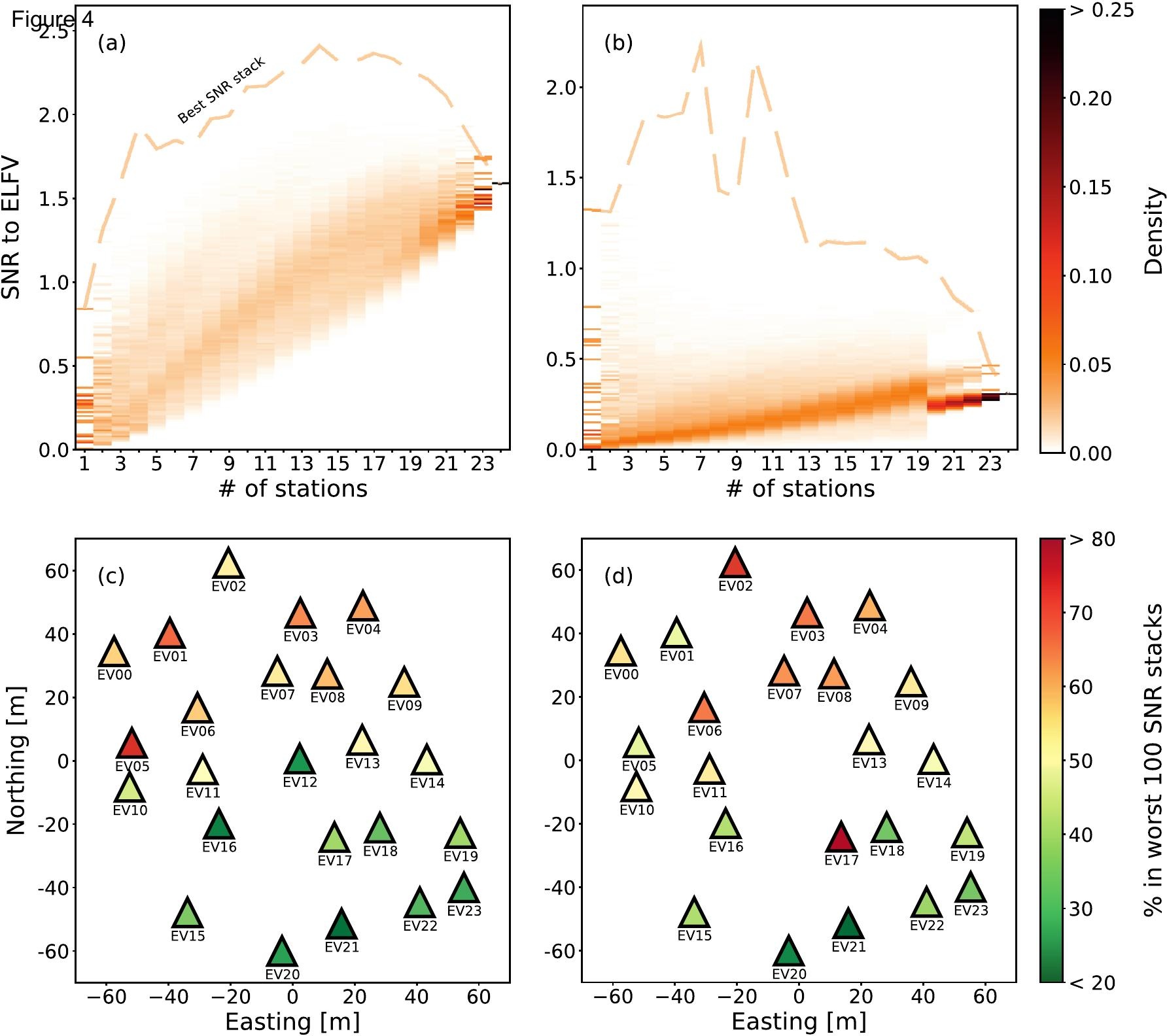


\section{Figure 5}

$24.80^{\circ} E \mid$

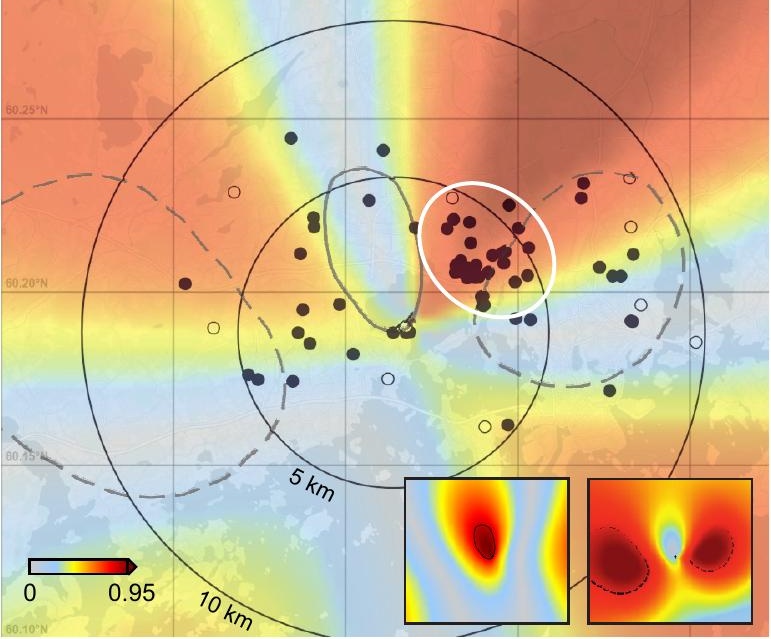




\section{Figure 6}

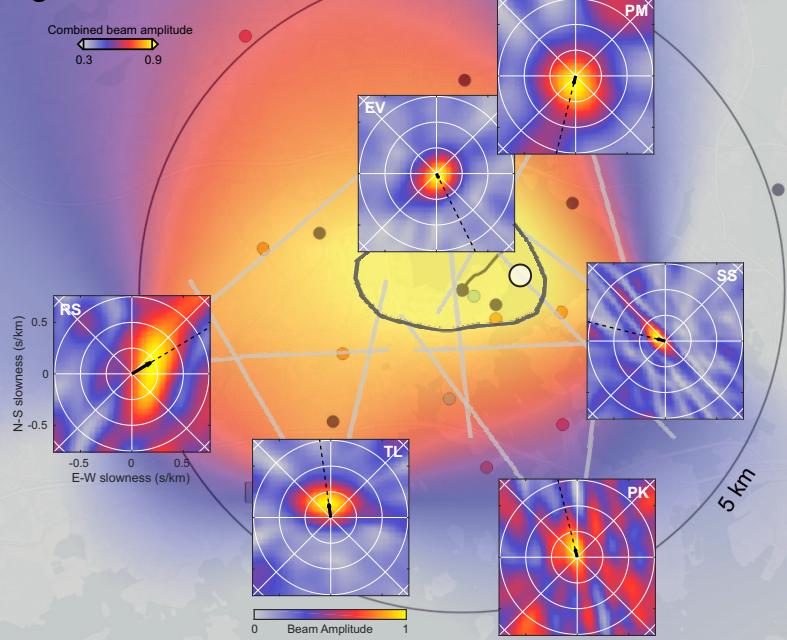



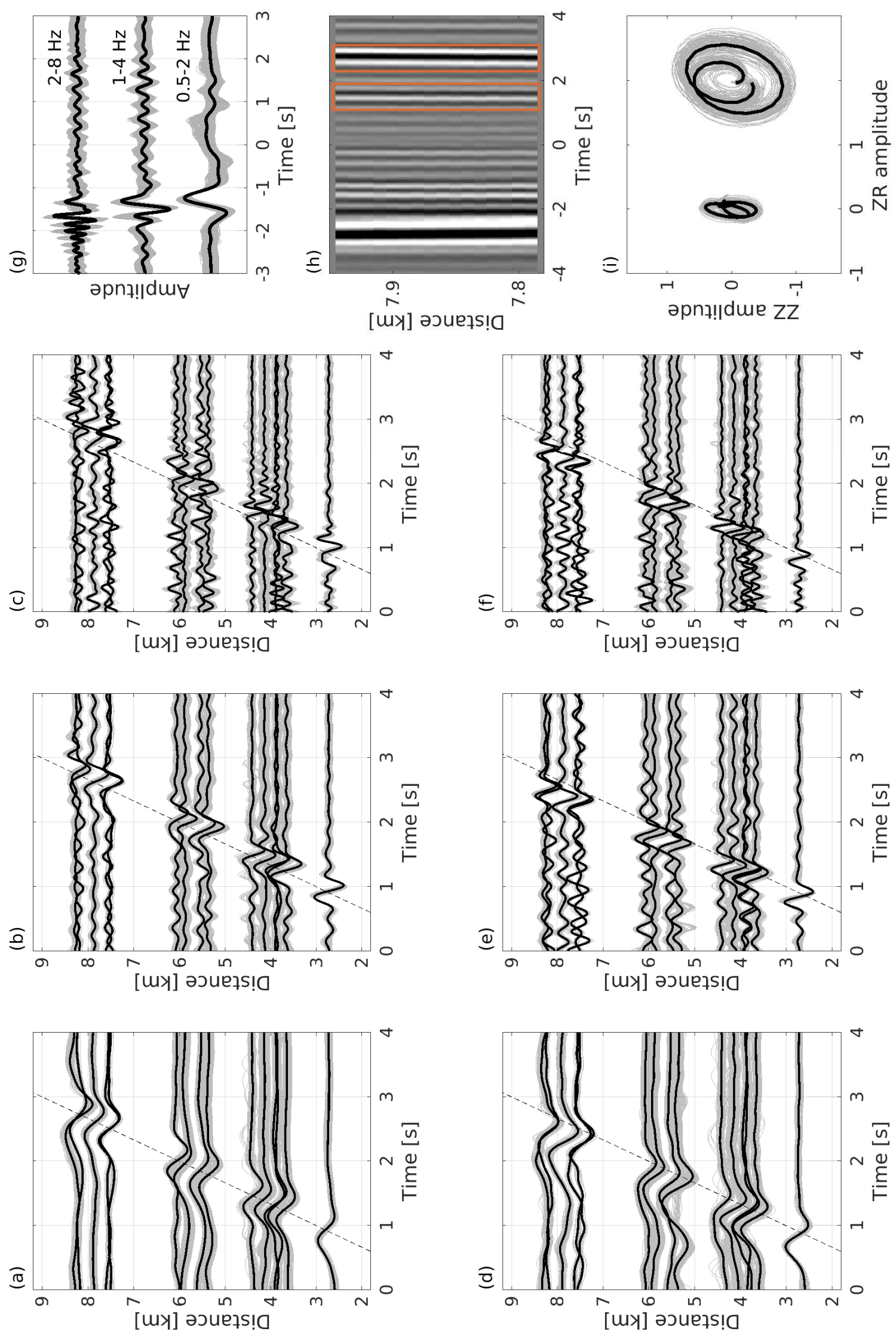


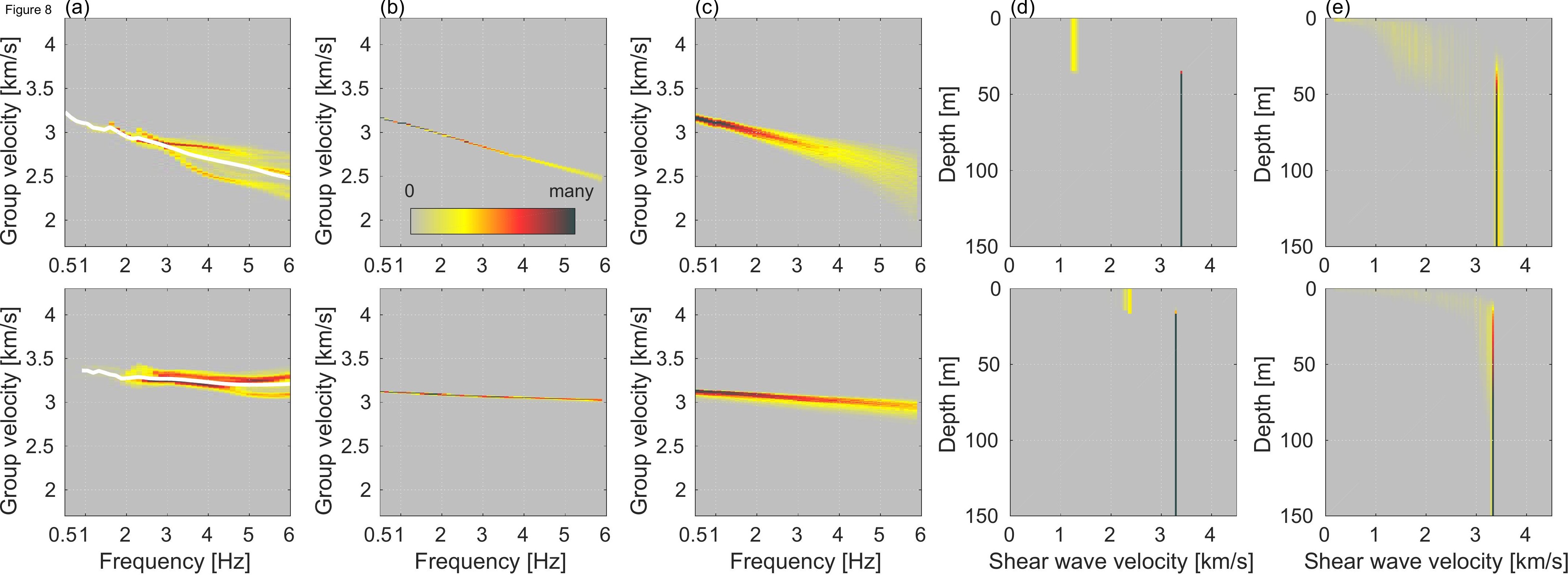


